EPJ Web of Conferences 106, 04016 (2016)

DOI: $10.1051 /$ epjconf/201610604016

(C) Owned by the authors, published by EDP Sciences, 2016

\title{
Analysis of Induced Gamma Activation by D-T Neutrons in Selected Fusion Reactor Relevant Materials with EAF-2010
}

\author{
Axel Klix ${ }^{1, a}$, Ulrich Fischer ${ }^{1}$, and Daniel Gehre ${ }^{2}$ \\ ${ }^{1}$ Karlsruhe Institute of Technology, Institute for Neutron Physics and Reactor Technology, 76344 \\ Eggenstein-Leopoldshafen, Germany \\ ${ }^{2}$ Technische Universitaet Dresden, Institute of Nuclear and Particle Physics, 01069 Dresden, Germany
}

\begin{abstract}
Samples of lanthanum, erbium and titanium which are constituents of structural materials, insulating coatings and tritium breeder for blankets of fusion reactor designs have been irradiated in a fusion peak neutron field. The induced gamma activities were measured and the results were used to check calculations with the European activation system EASY2010. Good agreement for the prediction of major contributors to the contact dose rate of the materials was found, but for minor contributors the calculation deviated up to $50 \%$.
\end{abstract}

\section{Introduction}

Activation of fusion reactor materials is an important issue from the viewpoint of licensing, safety, maintenance and decommissioning. The activation is produced mainly by fusion peak neutrons for which many reaction channels are open and by slow neutrons for which capture cross sections are very large. It is therefore necessary to investigate the induced activities of these materials in $14 \mathrm{MeV}$ neutron fields experimentally and apply the results to validate codes and data libraries used for R\&D work.

In the present work, we re-analyse previous experiments on activation of selected fusion reactor relevant materials with inventory calculations with the EASY package based on the inventory code FISPACT [1] and activation data from the EAF-2010 library [2]. In particular we consider the activation of lanthanum, erbium and titanium in a fusion peak neutron field. The activation experiments were done at the DT neutron generator laboratory of Technical University of Dresden and had been analysed previously with earlier versions of the EAF file [3, 4].

Lanthanum oxide is a candidate material for the heat shield in the divertor and therefore exposed to an intense fast neutron field. Erbium oxide was suggested as an insulating coating as well as a possible tritium barrier for liquid breeder blankets. Titanium is a constituent of structural materials but most notably present in the candidate breeder material lithium titanate $\left(\mathrm{Li}_{2} \mathrm{TiO}_{3}\right)$.

\footnotetext{
${ }^{a}$ Corresponding author: axel.klix@kit.edu
}

This is an Open Access article distributed under the terms of the Creative Commons Attribution License 2.0, which permits unrestricted use, distribution, and reproduction in any medium, provided the original work is properly cited. 

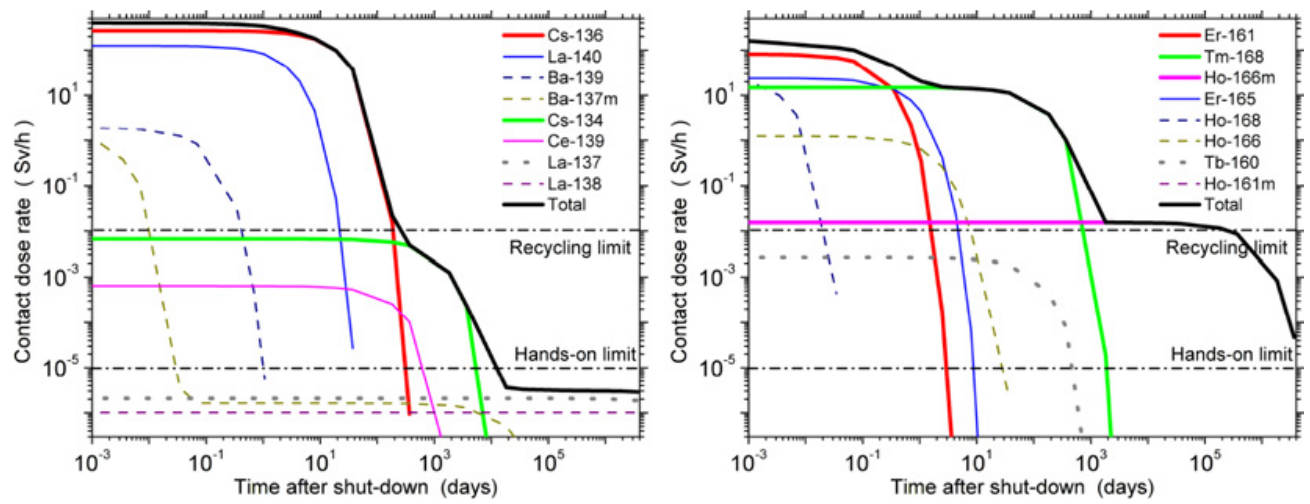

Figure 1. Shut-down $\gamma$-ray contact dose rates calculated for lanthanum (left) and erbium (right).

\section{Calculations to Estimate Shut-down Dose Behaviour in a Fusion Power Reactor}

Survey calculations with EASY-2010 applying a fusion peak neutron spectrum were conducted for all three materials to determine the main contributions to the contact dose rate which is a means to estimate waiting times before materials can be recycled or handled hands-on. The results of these survey calculations were compared with recycling and hands-on limits based on ICRP recommendations [5]. The FISPACT code calculates $\gamma$-ray contact dose rates at the surface of a semi-infinite slab following a scheme devised by Jaeger [6]. According to the experience of the authors, the beta dose rate at very short distances can be similar to the gamma dose rate.

Aim of the experimental investigation is to provide data for comparing model inventory calculations. However, there is no neutron source presently available which would permit such irradiation experiments under full reactor-like conditions. Instead one is limited to comparably short irradiation times and less neutron flux density. The irradiation facilities of choice are accelerator based DT neutron generators since their neutron field can be characterized very well. For the survey conditions presented in the following sections, power plant conditions were assumed which means a flux of $14 \mathrm{MeV}$ neutrons corresponding to a neutron wall loading of $1.0 \mathrm{MW} / \mathrm{m}^{2}$, for a period of one year. The 175 group activation library eaf_n_gxs_175_fus_20100 together with the eaf_dec_20100 decay library were used for the survey calculations and the calculations for comparison with experiment.

\subsection{Lanthanum}

The only stable isotope of lanthanum is ${ }^{139} \mathrm{La}$. After exposure to reactor-like conditions as described above, the contact dose rate, presented in Fig. 1, is dominated by ${ }^{140} \mathrm{La}$ and ${ }^{136} \mathrm{Cs}$ until the recycling limit is reached 200 days after shut-down. The remaining contact dose rate is dominated by ${ }^{134} \mathrm{Cs}$ and ${ }^{137 m} \mathrm{Ba}$ up to the hands-on limit which is reached after 50 years. ${ }^{137 m} \mathrm{Ba}$ is a radionuclide with a short half-life. After rapid decay of the initial population it is still fed by the presence of ${ }^{137} \mathrm{Cs}$ which is not contributing to the contact dose rate as calculated by EASY and therefore does not show up in Fig. 1. Long-term activity is mostly due to ${ }^{137} \mathrm{La}$ and ${ }^{138} \mathrm{La}$.

\subsection{Erbium}

Natural erbium consist of six isotopes, the composition is presented in Table 1. The evolution of the shut-down dose rate is also shown in Fig. 1. For the first ten days after shut-down, the contact dose rate 


\section{$15^{\text {th }}$ ISRD}

Table 1. Isotopic composition of the considered materials.

\begin{tabular}{|l|l|l|l|l|l|}
\hline \multicolumn{2}{|c|}{ La } & \multicolumn{2}{c|}{ Er } & \multicolumn{2}{c|}{ Ti } \\
\hline La-139 & $100 \%$ & Er-162 & $0.14 \%$ & Ti-46 & $8.2 \%$ \\
\hline & & Er-164 & $1.61 \%$ & Ti-47 & $7.4 \%$ \\
\hline & & Er-166 & $33.60 \%$ & Ti-48 & $73.8 \%$ \\
\hline & & Er-167 & $23.0 \%$ & Ti-49 & $5.4 \%$ \\
\hline & & Er-168 & $26.8 \%$ & Ti-50 & $5.2 \%$ \\
\hline & & Er-170 & $14.9 \%$ & & \\
\hline
\end{tabular}
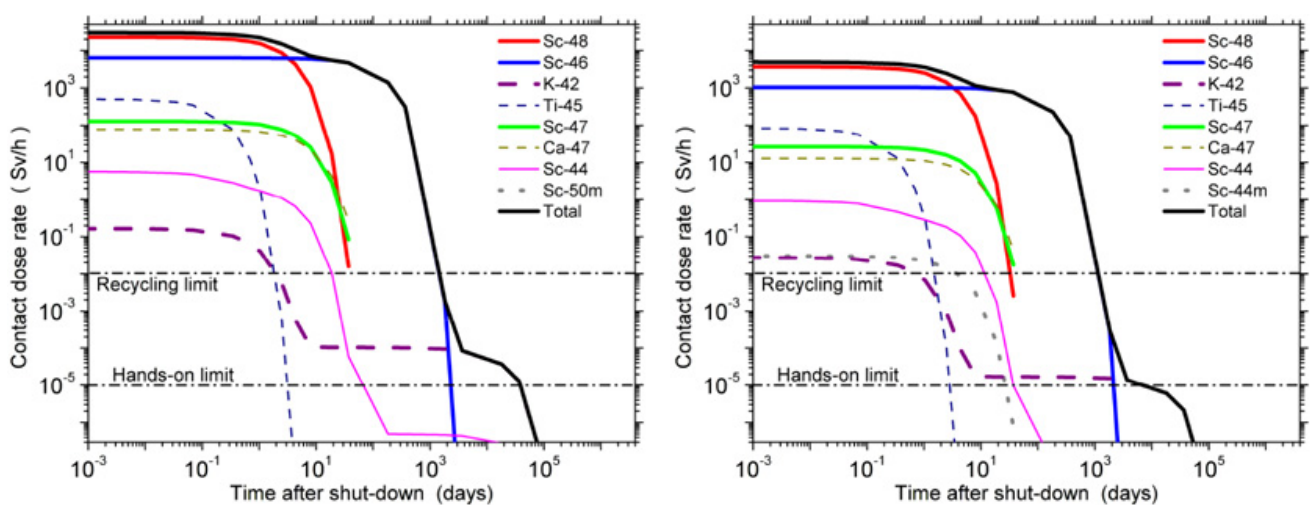

Figure 2. Shut-down $\gamma$-ray contact dose rates calculated for pure titanium (left) and $\mathrm{Li}_{2} \mathrm{TiO}_{3}$ (right).

is dominated by ${ }^{161} \mathrm{Er},{ }^{165} \mathrm{Er},{ }^{168} \mathrm{Tm}$. The latter contributes mostly to the dose rate for another 500 days. The recycling limit is finally reached after 1500 years with the decay of the metastable ${ }^{166 m}$ Ho (half-life 1200 years). The hands-on limit is reached after approximately 20000 years.

\subsection{Titanium and Lithium Titanate}

The isotopic composition of natural titanium is presented in Table 1. The calculated contact dose rates for pure titanium and also titanium titanate are shown in Fig. 2. Also in case of titanium the contact dose rate is mostly determined by a few radio isotopes. The important radio isotopes are ${ }^{48} \mathrm{Sc},{ }^{46} \mathrm{Sc},{ }^{42} \mathrm{~K}$. With these the recycling limit is reached after about $4.4 \mathrm{yr}$ and the hands-on-limit after about $109 \mathrm{yr}$. For lithium titanate these limits are reached a little earlier which is due to the "dilution" of the radio isotopes, lithium and oxygen produce no long-lasting radio isotopes under these conditions.

\section{Experiment}

The samples were foils of $\mathrm{La}, \mathrm{Er}$, and Ti with a purity of $99.9 \%$. They were irradiated at the DT neutron generator of Technical University of Dresden. The neutron generator is a deuterium accelerator with a deuteron energy of $320 \mathrm{keV}$ bombarding a titanium-tritium target. Samples were set up approximately $2.0 \mathrm{~cm}$ away from the neutron source in case of $\mathrm{Er}$ and $\mathrm{La}$, and $7.5 \mathrm{~cm}$ in case of Ti. The local neutron fluence at the sample position was determined with niobium foils attached to the front and back of each sample. In addition, $\mathrm{Zr}$ foils were used for the Ti sample since the combination of $\mathrm{Nb}$ and $\mathrm{Zr}$ dosimetry foils can provide information on the neutron spectrum which is important for the ${ }^{47} \mathrm{Ti}$ production. The production cross section of the latter reaction shows a sharp increase in the energy range of the typical DT fusion neutron peak. The calculated neutron spectrum in front of the tritium target of the neutron generator for the position of the Ti foils is shown in Fig. 3. 


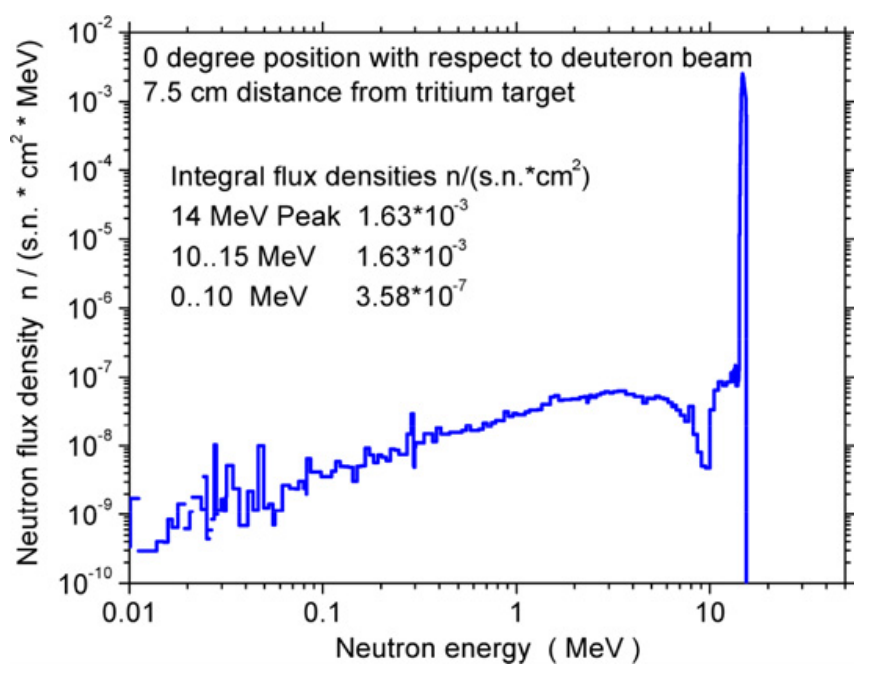

Figure 3. Neutron spectrum in the position of the Ti sample calculated with the DROSG and MCNP codes.

The cross section of the reaction ${ }^{93} \mathrm{Nb}(\mathrm{n}, 2 \mathrm{n}){ }^{92 \mathrm{~m}} \mathrm{Nb}$ was considered constant in the energy range $14-15 \mathrm{MeV}$ with a value of $464 \mathrm{mb}$ and an uncertainty of $4.2 \%$.

After neutron irradiation, gamma ray spectra were obtained with a high purity germanium (HPGe) detector at several times after irradiation. The attenuation of gamma-rays, which is appreciable especially at low gamma energies, was estimated by 3D Monte Carlo calculations.

\section{Results and Discussion}

For the analysis of the measured induced activities, a second calculation with the EASY system has been performed. The neutron spectrum applied in this calculation was obtained from a detailed MCNP calculation of the target assembly of the DT neutron generator. The results of experiment and calculation are presented in Tables 2-4.

Error estimates are also shown in the tables and these were calculated as follows:

$\triangle \mathrm{C} / \mathrm{C}$ is the relative error of the FISPACT calculation which includes the half-life time and cross section uncertainties from the EAF-2010 data.

$\Delta \mathrm{E} / \mathrm{E}$ is the experimental error which takes into consideration the uncertainties of the half-life and the gamma line intensity (strongly depending on isotope), detector efficiency (3\%), and counting error (typical $<1 \%$ ). Half-lives and gamma line intensities and their errors were taken from Refs. [2, 3].

The table includes also the uncertainty of the neutron flux measurement which was estimated to be $5 \%$ considering cross section uncertainty of the ${ }^{93} \mathrm{Nb}(\mathrm{n}, 2 \mathrm{n})^{92 \mathrm{~m}} \mathrm{Nb}$ reaction and errors due to the activity measurement.

\subsection{Lanthanum}

The nuclides ${ }^{136} \mathrm{Cs}$ and ${ }^{140} \mathrm{La}$ dominate the contact dose rates for the first 200 days after shut-down. These activities were measured. However, as in case of ${ }^{182} \mathrm{Ta},{ }^{140} \mathrm{La}$ is produced in a neutron capture reaction which could be better evaluated in a thermal neutron field rather than the fusion peak field of this experiment. ${ }^{136} \mathrm{Cs}$ and the minor dose rate contributor ${ }^{139} \mathrm{Ba}$ were predicted well. The long-term activation products ${ }^{134} \mathrm{Cs}$ and ${ }^{139} \mathrm{Ce}$ which determine the activity up to the hands-on limit could not be measured due to their low activity in the sample. 


\section{$15^{\text {th }}$ ISRD}

Table 2. Comparison of calculated and experimental radionuclide productions for lanthanum.

\begin{tabular}{|c|c|c|c|c|c|c|c|}
\hline Radio-nuclide & Half-life & $\mathbf{E} \gamma(\mathbf{k e V}) / \mathbf{I} \gamma$ & $\begin{array}{l}\text { Production } \\
\text { contribution (\%) }\end{array}$ & & $\mathrm{C} / \mathrm{E}$ & $\begin{array}{l}\Delta \mathbf{C} / \mathrm{C} \\
(\%)\end{array}$ & $\begin{array}{l}\Delta \mathbf{E} / \mathbf{E} \\
(\%)\end{array}$ \\
\hline Cs-136 & $13.16 \mathrm{~h}$ & $\begin{array}{l}1048.1 / 0.80 \\
340.5 / 0.42 \\
1235.4 / 0.20\end{array}$ & $\begin{array}{l}{ }^{139} \mathrm{La}(\mathrm{n}, \alpha){ }^{136} \mathrm{Cs} \\
{ }^{139} \mathrm{La}(\mathrm{n}, \alpha){ }^{136 m} \mathrm{Cs} \rightarrow \mathrm{IT} \rightarrow 136 \mathrm{Cs}\end{array}$ & $\begin{array}{r}94.3 \\
5.8\end{array}$ & 1.02 & 28 & 9.0 \\
\hline Ba-139 & $1.38 \mathrm{~h}$ & $165.9 / 0.238$ & ${ }^{139} \mathrm{La}(\mathrm{n}, \mathrm{p}){ }^{139} \mathrm{Ba}$ & 100.0 & 0.97 & 20 & 24.0 \\
\hline La-140 & $1.68 \mathrm{~d}$ & $\begin{array}{l}925.2 / 0.070 \\
867.8 / 0.056 \\
751.8 / 0.044\end{array}$ & ${ }^{139} \mathrm{La}(\mathrm{n}, \gamma){ }^{140} \mathrm{La}$ & 100.0 & 0.93 & 24 & 7.3 \\
\hline
\end{tabular}

Table 3. Comparison of calculated and experimental values for erbium.

\begin{tabular}{|c|c|c|c|c|c|c|c|}
\hline Radio-nuclide & Half-life & $\mathbf{E} \gamma(\mathbf{k e V}) / \mathbf{I} \gamma$ & $\begin{array}{l}\text { Production } \\
\text { contribution (\%) }\end{array}$ & & $\mathrm{C} / \mathrm{E}$ & $\begin{array}{l}\Delta \mathbf{C} / \mathbf{C} \\
(\%)\end{array}$ & $\begin{array}{l}\Delta \mathbf{E} / \mathbf{E} \\
(\%)\end{array}$ \\
\hline Er-161 & $3.21 \mathrm{~h}$ & $\begin{array}{l}826.6 / 0.64 \\
211.2 / 0.12 \\
592.6 / 0.04\end{array}$ & ${ }^{162} \mathrm{Er}(\mathrm{n}, 2 \mathrm{n}){ }^{161} \mathrm{Er}$ & 100.0 & 1.08 & 10 & 8.0 \\
\hline Но-167 & $3.10 \mathrm{~h}$ & $\begin{array}{l}346.5 / 0.57 \\
321.3 / 0.24 \\
237.9 / 0.05\end{array}$ & $\begin{array}{l}{ }^{167} \operatorname{Er}(\mathrm{n}, \mathrm{p})^{167} \mathrm{Ho} \\
{ }^{168} \operatorname{Er}(\mathrm{n}, \mathrm{d})^{167} \mathrm{Ho}\end{array}$ & $\begin{array}{l}84.7 \\
13.9\end{array}$ & 0.95 & 29 & 6.0 \\
\hline Но-168 & $3.0 \mathrm{~min}$ & $\begin{array}{l}741.3 / 0.36 \\
821.9 / 0.34 \\
815.9 / 0.18\end{array}$ & $\begin{array}{l}{ }^{168} \mathrm{Er}(\mathrm{n}, \mathrm{p})^{168} \mathrm{Ho} \\
{ }^{168} \mathrm{Er}(\mathrm{n}, \mathrm{p})^{168 m} \mathrm{Ho} \\
{ }^{170} \mathrm{Er}(\mathrm{n}, \mathrm{t}){ }^{168} \mathrm{Ho}\end{array}$ & $\begin{array}{l}84.7 \\
13.3 \\
0.95\end{array}$ & 1.36 & 58 & 9.3 \\
\hline Ho-170 & $2.8 \mathrm{~min}$ & $931.8 / 0.35$ & ${ }^{170} \mathrm{Er}(\mathrm{n}, \mathrm{p}){ }^{170} \mathrm{Ho}$ & 100.0 & 0.64 & 30 & 18 \\
\hline Er-163 & $1.25 \mathrm{~h}$ & $1113.5 / 4.9 \mathrm{E}-4$ & ${ }^{164} \mathrm{Er}(\mathrm{n}, 2 \mathrm{n}){ }^{163} \mathrm{Er}$ & 100.0 & 0.77 & 20 & 8.0 \\
\hline Но-166 & $1.2 \mathrm{yr}$ & $\begin{array}{l}1379.4 / 0.009 \\
1581.9 / 0.002 \\
1662.4 / 0.001\end{array}$ & $\begin{array}{l}{ }^{166} \mathrm{Er}(\mathrm{n}, \mathrm{p})^{166} \mathrm{Ho} \\
{ }^{167} \operatorname{Er}(\mathrm{n}, \mathrm{d})^{166} \mathrm{Ho}\end{array}$ & $\begin{array}{l}93.1 \\
6.7\end{array}$ & 0.90 & 29 & 7.3 \\
\hline Tm-168 & $93.1 \mathrm{~d}$ & $\begin{array}{l}720.4 / 0.119 \\
741.4 / 0.123 \\
816.0 / 0.490\end{array}$ & $\begin{array}{l}{ }^{170} \operatorname{Er}(\mathrm{n}, 2 \mathrm{n}) \text { followed by } \\
{ }^{169} \operatorname{Er}(\mathrm{b}-)^{169} \operatorname{Tm}(\mathrm{n}, 2 \mathrm{n})\end{array}$ & & $1.04 \mathrm{E}-3$ & - & 5.0 \\
\hline
\end{tabular}

\subsection{Erbium}

The activity of ${ }^{161} \mathrm{Er}$, the most important nuclide for the first few hours after shut-down, was predicted well within the experimental error using the strongest gamma line.

A huge underestimation of the calculation was found for ${ }^{168} \mathrm{Tm}$. It is important to consider this isotope since it dominates the contact dose rate from one day to one year after shut-down. Under reactor conditions, ${ }^{168} \mathrm{Tm}$ is produced by the reaction chain ${ }^{170} \mathrm{Er}(\mathrm{n}, 2 \mathrm{n}){ }^{169} \mathrm{Er}$ followed by beta- decay with a half-life time of 9 days. The resulting ${ }^{169} \mathrm{Tm}$ is subjected to $(\mathrm{n}, 2 \mathrm{n})$ reaction to ${ }^{168} \mathrm{Tm}$. There are some contributions from sequential charged particle reactions on ${ }^{168} \mathrm{Er}$ as well. However, the only stable isotope of Tm, ${ }^{169} \mathrm{Tm}$, may be present in Er as an impurity. An analysis of the samples is underway. The production of ${ }^{167} \mathrm{Ho}$ is very well predicted by the calculation and even within the experimental uncertainty. The nuclides ${ }^{165} \mathrm{Er}$ and ${ }^{166 m} \mathrm{Ho}$ could not be measured in this experiment.

\subsection{Titanium}

The production of the two scandium isotopes 46 and 47 was predicted quite well. The ${ }^{47} \mathrm{Sc}$ production was overestimated by $13 \%$. However the FISPACT calculation also has a relatively high uncertainty.

It should be noted that the production cross section of ${ }^{47} \mathrm{Sc}$ from natural titanium has a contribution from ${ }^{47} \mathrm{Ti}$ via the $(\mathrm{n}, \mathrm{p})$ and ${ }^{48} \mathrm{Ti}$ via the $(\mathrm{n}, \mathrm{d})$ and $(\mathrm{n}, \mathrm{np})$ reactions, see table 4 . The cross sections for both of these reactions are rising quickly at around $14 \mathrm{MeV}$ neutron energy, so that a slight deviation of the 
Table 4. Comparison of calculated and experimental values for titanium.

\begin{tabular}{|c|c|c|c|c|c|c|c|}
\hline Radio-nuclide & Half-life & $\mathbf{E} \gamma(\mathbf{k e V}) / \mathbf{I} \gamma$ & $\begin{array}{l}\text { Production } \\
\text { contribution }(\%)\end{array}$ & & $\mathbf{C} / \mathbf{E}$ & $\begin{array}{l}\Delta \mathrm{C} / \mathrm{C} \\
(\%)\end{array}$ & $\begin{array}{l}\Delta \mathrm{E} / \mathrm{E} \\
(\%)\end{array}$ \\
\hline Sc-46 & $83.79 \mathrm{~d}$ & $\begin{array}{l}889.3 / 1.00 \\
1120.5 / 1.00\end{array}$ & $\begin{array}{l}{ }^{46} \mathrm{Ti}(\mathrm{n}, \mathrm{p})^{46} \mathrm{Sc} \\
{ }^{46} \mathrm{Ti}(\mathrm{n}, \mathrm{p}){ }^{46 m} \mathrm{Sc} \rightarrow \mathrm{IT} \rightarrow{ }^{46} \mathrm{Sc} \\
{ }^{47} \mathrm{Ti}(\mathrm{n}, \mathrm{d})^{46} \mathrm{Sc}+{ }^{47} \mathrm{Ti}(\mathrm{n}, \mathrm{np}){ }^{46} \mathrm{Sc} \\
{ }^{47} \mathrm{Ti}(\mathrm{n}, \mathrm{d})^{46 m} \mathrm{Sc}+{ }^{47} \mathrm{Ti}(\mathrm{n}, \mathrm{np})^{46 m} \mathrm{Sc} \\
\rightarrow \mathrm{IT} \rightarrow{ }^{46} \mathrm{Sc}\end{array}$ & $\begin{array}{c}64.58 \\
15.67 \\
16.84 \\
\\
2.91\end{array}$ & 0.93 & 24 & 3.4 \\
\hline Sc-47 & $3.351 \mathrm{~d}$ & $159.4 / 0.68$ & $\begin{array}{l}{ }^{47} \mathrm{Ti}(\mathrm{n}, \mathrm{p})^{47} \mathrm{Sc} 40.19 \\
{ }^{48} \mathrm{Ti}(\mathrm{n}, \mathrm{d})^{47} \mathrm{Sc}+{ }^{48} \mathrm{Ti}(\mathrm{n}, \mathrm{np})^{47} \mathrm{Sc}\end{array}$ & 59.80 & 1.13 & 49.2 & 4.2 \\
\hline Sc-48 & $1.8196 \mathrm{~d}$ & $\begin{array}{l}983.5 / 1.00 \\
1037.5 / 0.975 \\
1312.1 / 1.00\end{array}$ & $\begin{array}{l}{ }^{48} \mathrm{Ti}(\mathrm{n}, \mathrm{p}){ }^{48} \mathrm{Sc} \\
{ }^{49} \mathrm{Ti}(\mathrm{n}, \mathrm{d})^{48} \mathrm{Sc}+{ }^{49} \mathrm{Ti}(\mathrm{n}, \mathrm{np}){ }^{48} \mathrm{Sc}\end{array}$ & $\begin{array}{c}99.01 \\
0.99\end{array}$ & 0.98 & 10 & 4.3 \\
\hline
\end{tabular}

calculated neutron spectrum, which is the base for the FISPACT calculation, may be the cause besides an uncertainty in the production cross section.

\section{Conclusions}

The most important contributions to the total $\gamma$-ray dose rate from activities induced in a fusion peak neutron field in the elements La, Er, and Ti were predicted well by the activation system EASY-2010 up to the recycling limit. Despite a higher uncertainty, nuclides originating from neutron capture reactions were predicted within $20 \%$ of the experimental value although the experiment was not designed to test such reactions. Nuclides responsible for most of the activity after the recycling limit is reached could not be measured in these experiments due to their low activity in the samples. A large underestimation of the calculation was found for ${ }^{168} \mathrm{Tm}$ in Er suggesting ${ }^{169} \mathrm{Tm}$ as an important impurity in Er which is currently under investigation.

Parts of the work, supported by the European Communities under the contract of Association between KIT-Euratom, were carried out within the framework of the European Fusion Development Agreement. The views and opinions expressed herein do not necessarily reflect those of the European Commission.

\section{References}

[1] RA Forrest, 'FISPACT-2007: User manual', UKAEA FUS 534, 2007

[2] J.-Ch. Sublet, L.W. Packer, J. Kopecky, R.A. Forrest, A.J. Koning and D.A. Rochman, The European Activation File: EAF-2010 neutron-induced cross section, EASY Documentation Series CCFE-R (10) 05, Neutron cross sections: Issue 1, CCFE, 2010

[3] A. Klix, R. Eichin, R.A. Forrest, H. Freiesleben, K. Schomburg, K. Seidel, S. Unholzer, Fus. Eng. Des. 82, 2558 (2007)

[4] A. Klix, A. Domula, R. Forrest, K. Zuber, J. Nucl. Mat. 417, 688 (2011)

[5] ICRP recommendations, ICRP publication 60, Annals of the ICRP 21,1990

[6] R.G. Jaeger (Editor-in-Chief), 'Engineering Compendium on Radiation Shielding', Vol. 1, Springer-Verlag, 1968 